\title{
Políticas neoliberales y radiodifusión estatal en México
}

\section{Neoliberal Policies and Public Broadcasting in Mexico}

\section{- Lenin Martell Gámez}

Universidad Autónoma del Estado de México

Fecha de recepción: 2 de noviembre de 2018

Fecha de aprobación: 3 de diciembre de 2018

\section{NOTAS BIOGRÁFICAS}

Lenin Martell Gámez es profesor de Ciencias Políticas y Sociales en la UAEM. Doctor en Ciencias Políticas y Sociales por la UNAM, magister en Comunicación de Masas por la Boston University y licenciado en Periodismo y Comunicación colectiva por la UNAM. Miembro del Comité de la defensoría de las audiencias de Radio Educación.

Contacto: leninmartell@gmail.com

\section{Resumen}

Este trabajo analiza el desarrollo de la radiodifusión estatal en México en el contexto de las políticas neoliberales durante el siglo XX y principios del XXI. En dicho recorrido histórico, se examina cómo el Estado mexicano no se preocupó por generar políticas que respaldaran un desarrollo sólido de la radiodifusión de servicio público. Por el contrario, los diferentes gobiernos federales y estatales sólo abonaron a la creación de emisoras pertenecientes al sistema estatal de radiodifusión, pero la mayoría de éstas fueron utilizadas como medios propagandísticos.

La discusión planteada en este texto es fundamental para entender cómo se fue gestando, durante este periodo histórico, la relación entre los medios estatales, el Estado y la sociedad. Asimismo, es importante para conocer cómo, en las últimas décadas del siglo XX y principios del XXI, se fue intensificando un debate social y político sobre la necesidad de tener medios públicos y autónomos con respecto del gobierno, que contribuyeran al desarrollo local y nacional.

\section{Abstract}

This work analyses the public media development in Mexico within the context of the neoliberal policies during the 20th century and the beginnings of the 21st. Through a historical approach, the author examines how the Mexican State was not interested in creating policies, which motivated the solid growth of public service media. On the contrary, different federal and state governments only created local broadcasting systems, but most of them were utilized as propaganda.

This paper becomes crucial to understanding how the State media, the State, and society structured a relationship during this historical period. It is also fundamental in order to learn how these three social actors intensified a conversation-in the last decades of the 20th and the first of this century-on the need of developing an independent public media system which contributed to both the local and national development. 


\section{Palabras clave}

Medios públicos, servicio público de radiodifusión, políticas culturales y de comunicación, historia de los medio públicos.

\section{Keywords}

Public media, public service broadcasting, cultural and communication policies, public media history.

\section{Sumario}

\section{Antecedentes}

2. Radiodifusión estatal en México en tiempos del neoliberalismo

3. I. Reordenamiento en la estructura de los medios estatales y las políticas liberales: 1982-1988

4. II. $1988-1994$

5. III. 1994-2000

6. IV. 2001-2006

7. Sistema de radiodifusión estatal en el nuevo siglo

8. Reflexiones finales

\section{Contents}

1. Background

2. Public broadcasting in Mexico in times of neoliberalism

3. I.Reorganization in the structure of public media and liberal policies 1982-1988

4. II.1988-1994

5. III. 1994-2000

6. IV. 2001-2006

7. Public broadcasting systems in the new century.

8. Final thoughts 


\section{ANTECEDENTES}

Este trabajo tiene como objetivo analizar el desarrollo de la radiodifusión estatal en México en el contexto de las políticas neoliberales durante el siglo XX y principios del XXI, a través de una perspectiva histórica. Específicamente, parto de la premisa de cómo el Estado mexicano no se preocupó por generar políticas culturales que respaldaran un desarrollo sólido de la radiodifusión de servicio público; por el contrario, los diferentes gobiernos federales y estatales sólo abonaron a la creación de emisoras pertenecientes al sistema estatal de radiodifusión, pero la mayoría de éstas fueron utilizadas como medios de propaganda.

Vincular la radiodifusión estatal con la noción de servicio público ha sido una de las preocupaciones de varios Estados nacionales desde el siglo XX, y se hizo presente en México a finales de la década de los 70. Proviene del hecho de que cualquier tipo de servicio público (educación; vivienda; cultura; salud,...) se circunscribe en las sociedades contemporáneas como un servicio que brinda el Estado con el fin de garantizar el bienestar de la sociedad y fundamentalmente el del ciudadano. El Estado amplía sus funciones y garantiza a los ciudadanos una mejor calidad de vida, lo que permite impulsar el desarrollo social (Martell, 2017).

El servicio público de radio es tan importante como los otros garantizados por el Estado porque contribuye a fortalecer la identidad nacional, a que los ciudadanos participen del debate público y que hagan práctica de la libertad de expresión. Este servicio adquiere importancia en el Reino Unido y en el norte de Europa a finales de los años 20 y en algunos otros países de la mancomunidad británica (Canadá, Australia y Nueva Zelanda) en los años 30. Sus fines, sin embargo, se inspiran en los ideales de fraternidad, igualdad y libertad de la Revolución francesa del siglo XVIII-valores que se extrapolan en el siglo XX en diversas naciones del mundo y que constituyen el cimiento en el que el Estado se basa para promover el bienestar social -(Ortega, 2006, p. 201). Después de la guerra, algunos países de Europa desarrollaron una economía más avanzada que les otorgó condiciones para poder vivir en un sistema relativamente estable con gobiernos liberales democráticos y esto contribuyó a que los Estados nacionales europeos impulsaran políticas con el fin de ampliar el bienestar de los ciudadanos. Estas circunstancias económicas y políticas permitieron que los Estados europeos del centro y norte de Europa (finales de los 20) consolidaran la expansión de los sistemas de medios públicos.

La naturaleza del servicio público está vinculada intrínsecamente al Estado, porque es la entidad que lo garantiza y establece la relación normativa. Empero no se limita ahí, sino en el cumplimiento de sus funciones, y en la voluntad de la sociedad en general para que éstas se lleven a cabo. Asimismo, en la participación de la ciudadanía en la definición de sus valores y objetivos (Serrano, 2006). Es decir, en la medida en que el servicio público amplía las posibilidades del espacio público y orienta satisfacciones de necesidades sociales de la población, potencia sus alcances como un bien social. Específicamente en América Latina, la perspectiva sobre la noción de servicio público de radiodifusión ha variado de país en país de acuerdo con sus formas sociohistóricas y culturales propias.

En realidad, hasta la fecha, lo que predomina en la región es una radio estatal, cultural, comunitaria, universitaria o sin fines de lucro, pero no una radio pública. Existe una radio no comercial que se ha caracterizado por su dependencia política con respecto de los gobiernos y por su atraso tecnológico. Esta situación ha generado una discusión entre radioastas, directores de emisoras y otros especialistas de América Latina sobre la autonomía política que debe ganar esta radio con respecto de los gobiernos. Por ejemplo, en el siglo XXI, en Colombia, ha habido un avance en el marco jurídico, el cual define la función del Estado en los medios de radiodifusión. Sin embargo, la existencia de esta condición jurídica no ha sido suficiente para que las radios estatales sean autónomas con respecto al gobierno (Quiroz, 2000, p. 383).

En el siglo XXI, la preocupación sobre el papel del Estado frente a la radio estatal en la mayoría de los países de esta región ha sido motivo de un debate intenso en grupos de académicos y periodistas. Sobre todo, debido a la importancia que tiene el servicio público para ejercer, entre otras cuestiones, la práctica cotidiana del derecho público a la información y a la libertad de expresión de los ciudadanos.

La preocupación por la situación de la radiodifusión estatal se intensificó en este siglo, como parte del discurso promocional de los gobiernos de centro izquierda que paulatinamente empezaron a llegar al poder en varios países latinoamericanos. Hubo preocupación por los gobiernos, como el de Argentina, acerca de 
cómo poner en marcha políticas culturales que fortalecieran el desarrollo democrático de los países.

Particularmente, en relación con la radiodifusión pública, los cuestionamientos giraron en torno a: financiar y legislar estos sistemas con el fin de sanear su funcionamiento normativo; construir audiencias más plurales y universales; lograr independencia editorial.

El rol del Estado en el servicio público-no sólo el de radiodifusión-era importante retomarlo dentro de un discurso que promovía valores públicos como la participación ciudadana, la igualdad social y el acceso universal a la información en un contexto social de la llamada era digital. Esto era cierto sobre todo en un momento histórico en el que los gobiernos predecesores, específicamente aquellos neoliberales de la década de los 90, habían favorecido las dinámicas del libre mercado.

Particularmente en México, hasta la primera década del siglo XXI, el Estado mexicano no se había preocupado por desarrollar la radiodifusión como un servicio público. Había creado emisoras estatales y culturales, pero con la ausencia de una política de Estado hacia la radiodifusión pública. Para entonces no había un marco jurídico que asociara a la radiodifusión con el servicio público y que definiera la noción de servicio público. En el artículo cuarto de la Ley Federal de Radio y Televisión de 1960, se leía: "La radio y la televisión constituyen una actividad de interés público, por lo tanto, el Estado deberá protegerla y vigilarla para el debido complimiento de su función social". El artículo no define qué es interés público, ni cómo el Estado deberá realizar su protección y vigilancia; tampoco, cuál y en qué consiste la función social.

Varias son las razones por las cuales el Estado no se interesó en impulsar la radiodifusión pública; éstas tienen su origen en los inicios de la radio en México en los años 20. Diversos especialistas coinciden en que el desarrollo histórico de la radio en México siguió el modelo norteamericano (Alva de la Selva, 1982; Fernández, 1982; Cortés e Ibargüengoitia, 2009, entre otros).

Al igual que en Estados Unidos, la radio en México nació mixta (modelo comercial y estatal), aunque con el predominio de la industria privada. Para Cortés e Ibargüengoitia (2009, p. 17) “...la vecindad y las relaciones económicas con este país influyeron de manera decisiva en la adopción del modelo privado y comercial que la radio siguió en este territorio". También es cierto que el gobierno de Álvaro Obregón no contaba con los recursos para desarrollar una nueva industria y tuvo que confiar el crecimiento de la radio al capital privado (Fernández, 1991, pp. 88-89).

Desde principios de la década de los 40 , las alianzas de empresarios y la participación minoritaria del Estado en este sector marcaron la expansión de la radio comercial en el siglo XX. Alva de la Selva (1988, p. 130), Fernández (1991, pp. 34-43), y más reciente Cortés e Ibargüengoitia (2009: 24-26), entre otros, coinciden en que estas alianzas permitieron que la radio comercial creciera exponencialmente tanto en programación como en comercialización. En estos años, la radiodifusión comercial acaparó el cuadrante y se consolidó como un negocio muy lucrativo en el que participaban tan sólo unas familias, quienes fueron consolidando grupos y quienes tenían injerencia en la vida política y económica nacional. Como ejemplo se encuentra la fundación de Radio Programas de México (RPM) conformada por Emilio Azcárraga y Clemente Serna en 1941; corporación que "Ilegó a [...] cubrir casi la mitad de las estaciones existentes en el país" (Alva de la Selva, 1988, p. 130). El fortalecimiento de los grupos empresariales desde los años 40 condujo a hechos como la concentración del capital primero en la radio y luego en la televisión. Asimismo, tuvo otras consecuencias como "incidir en los procesos legislativos garantizando condiciones favorables para la expansión de los mercados" (Fernández, 2000, pp. 121-122). Entre estos investigadores existe un amplio consenso sobre el hecho que, mientras el Estado apoyó el despliegue del modelo comercial, la radio y televisión estatal quedaron relegadas a un segundo plano por el Estado mexicano y desvinculados de una política de comunicación social. Sólo hubo algunos pequeños esfuerzos por parte del Estado, pero que no fueron suficientes para desarrollar los medios locales y estatales en el país:

- A principio de los años 20 el Estado mexicano intentó impulsar un sistema mixto de radiodifusión; fundó sus propias estaciones y dio facilidades a los particulares para crear las suyas. Las emisoras de titularidad estatal servirían principalmente para difundir información noticiosa y pronósticos del tiempo. Para darle institucionalidad a esta política, se creó el Departamento de Radio, suscrito a la Dirección General de Telégrafos de la Secretaría de Comunicaciones y Obras Públicas. Mejía (1989, p. 29) documenta que el gobierno hizo incluso donaciones de equipo a organizaciones sindicales 
para que establecieran sus estaciones: CROM, Federación Obrera Hidalguense de Pachuca, Centro Obrero Progresista de Jeréz Zacatecas, la Escuela de Ciegos y el Hospicio de Niños. Pero los intentos no progresaron, salvo por las radiodifusoras CZA y la CZZ, instaladas en 1923.

El 30 de noviembre de 1924, la Secretaría de Educación Pública inauguró la estación CZE, pero sus trasmisiones duraron cinco años. Para Alva de la Selva (1982), la emisora no tuvo mayor impacto en la sociedad y su fracaso se debió al poco tiempo que estuvo al aire y a la inestabilidad política y económica que vivía el país. Es hasta comienzos de los años 30, cuando la radiodifusora regresó al aire, pero con las siglas XFX (Mejía, 2007). Alva de la Selva documenta otros intentos para fundar radios estatales, como el Departamento Autónomo de Publicidad y Propaganda (DAPP) y la XEFO, fundada en 1931 por el Partido Nacional Revolucionario, "que con una emisora de la Secretaría de Educación Pública, se enfrentaba al bloque de la industria radiofónica comercial, entonces en su mayor auge" (Alva de la Selva, 1988, p. 43).

- El 27 de mayo de 1941, Jalisco se convirtió en el primer estado en impulsar una emisora estatal, pues los anteriores esfuerzos habían sido desde el centro y la federación. La XEJB transmitía en onda corta, pero el 1 de febrero de 1960 transitó a la FM. De acuerdo con Romo, la XEJB fue una iniciativa del gobernador de Jalisco, Silvano Barba, quien "la concebía como un instrumento propagandístico" (Romo, 1990, p. 68).

- Aparte de éstas, por varias décadas no hubo otras experiencias de radio estatal. Fue hasta 1968, que la XEEP, Radio Educación, reinició sus trasmisiones en la ciudad de México. La emisora fue creada como un órgano desconcentrado de la Secretaría de Educación Pública (Romo, 1990: 62).

- Además de la XEEP y la XEJB de Jalisco, hubo otra experiencia de radio estatal en el país: el 12 de octubre de 1973, el gobierno de Aguascalientes abrió las puertas de la XENM; la radio nació con fines culturales y, con el tiempo, la emisora amplió sus horizontes a la información (Romo, 1990, p. 70) El presidente Luis Echeverría puso en marcha una política gubernamental de comunicación. Sin embargo, su política no fue suficiente para evitar una mayor concentración de la radio comercial:

...Ocurrió un proceso de concentración del medio, de tal manera que para 1977, 15 grupos controlaban 84 por ciento de las estaciones comerciales en México. En 1970 había 604 estaciones de radio en el país, de las cuales 580 eran comerciales y 24 culturales; en 1975 eran un total de 696 (668 comerciales y 24 culturales). (Sánchez Ruíz, 2005, p. 411).

-José López Portillo apoyó la creación de radiodifusoras y televisoras culturales en todo el país a través de la Dirección General de Radio, Televisión y Cinematografía (Cortés e Ibargüengoitia, 2009, p. 30). De las 24 emisoras culturales, 11 eran estatales y pertenecían a los gobiernos de Nuevo León, Campeche, Sonora y Guanajuato (Romo, 1990, pp. 60-61), además de Nayarit. Estas emisoras pretendían ser un medio de comunicación entre los ciudadanos y el gobierno, así como fomentar el desarrollo cultural de las localidades; sin embargo, el desempeño de cada estación varió de estado a estado. Según evalúa Romo (1990, pp. 74-77), la XHHB-Radio Sonora brindó un amplio servicio a diferentes sectores sociales con programas informativos y de difusión de la cultura; la XECU de Campeche se inclinó por contenidos culturales; en las emisoras de los estados de Nuevo León y Guanajuato se emuló a la programación de las radios comerciales. En Guanajuato las estaciones arrancaron con deficiencias en la producción y programación debido al desinterés del gobierno.

- En 1979, el Gobierno federal sumó tres estaciones a la radiodifusión estatal al adquirir las XEMP, XERPM y XEB del Grupo Radio Fórmula, el cual tenía problemas económicos desde 1976. Mejía denomina a esta modalidad, radio comercial-estatal. Para Sánchez Ruíz (2005, p. 421), "entre diciembre de 1978 y febrero de 1979 las secretarías de Hacienda y de Comunicaciones y Transportes decidieron adscribir las estaciones a la Secretaría de Gobernación, donde serían encargadas para su operación a la Dirección de Radio, Televisión y Cinematografía". Estas tres estaciones serían el pilar sobre el que se constituiría el Instituto Mexicano de la Radio en el siguiente sexenio (Mejía, 2007).

Al hacer un recuento sobre este periodo, Sánchez Ruíz explica que "el intervencionismo del sexenio echeverrista se vio atemperado durante el de López Portillo, aunque no se pasó a un modelo neoliberal propiamente" (Sánchez Ruíz, 2005, p. 418).

Primero con Echeverría y luego con López Portillo se inició el desarrollo de los medios estatales en el marco de una estrategia gubernamental de medios de comunicación. Sin embargo, esta medida se llegó a consolidar como una política de Estado que promoviera la autonomía 
política y financiera a la radiodifusión estatal, e incluso que se le ligara con funciones propias de un sistema de radiodifusión pública. Por el contrario, la mayor parte de las instituciones de la educación y la cultura, incluso la escuela, obviaban la discusión de las problemáticas culturales; la relacionaban más bien con una visión culturalista como el folclor, la anécdota, las tradiciones, las bellas artes, por citar algunos ejemplos. La presencia de la cultura en los medios de comunicación audiovisual tanto privados como estatales era también escasa; uno de los pocos espacios que habitaban en los medios audiovisuales era el Canal 8 de Televisa en los años 80 , aunque las producciones culturales y educativas eran provistas por la SEP y TV UNAM. Para autores como Toussaint (1985, pp. 49-51), su visión sobre la cultura era estrecha e incluso tendenciosa.

\section{LA RADIODIFUSIÓN ESTATAL EN MÉXICO EN TIEMPOS DEL NEOLIBERALISMO}

A finales de los 80 , el proceso de globalización-sobre todo en los países industrializados-permeó las estructuras políticas y económicas, minimizando el poder del Estado en las decisiones políticas, para quien las leyes del libre mercado en ocasiones resultaban más fuertes que su poder de decisión. Los políticos impulsaron políticas que beneficiaban al grupo en el poder y a sus propios intereses privados. Los medios de comunicación fueron utilizados para estos fines, mientras que los ciudadanos se alejaban de esta manera del ámbito político. Los medios acapararon cada vez más el debate en el espacio público y excluyeron de la discusión a amplios sectores de la población, lo cual contribuyó a la colonización del espacio privado en el espacio público y a generar desigualdades sociales y culturales, sobre todo en el nivel local. Esto se debió a que, en esta década, el capitalismo se revitalizó dentro de un esquema global, cuyo eje político-económico sería a partir de entonces el neoliberalismo ${ }^{2}$ (Calvento, 2006, p. 42).

En el contexto del neoliberalismo, la presencia del Estado en el espacio público disminuye mientras crece la influencia de otros grupos empresariales nacionales y multinacionales, los cuales hacen alianzas con grupos políticos y económicos en el poder, para beneficiar el interés privado. La transformación del espacio público en el neoliberalismo se encuentra en el ámbito político, debido a su influencia en el espacio público. Lo político hace la diferencia entre lo público y lo privado; es desde lo privado -y del seno de la familia $u$ otras instituciones socialzantes como la escuela o la iglesia- donde lo político se empieza a articular, porque es ahí donde "se crean condiciones favorables para crear un clima de discusión y consenso, que es precisamente lo que caracteriza a cualquier espacio público" (Ortega, 2004, p. 9). Este proceso -privado-político-público- ocurre todavía en el seno del neoliberalismo, aunque, a medida que la política ha cobrado un significado diferente en la escena del capitalismo, lo público ha quedado debilitado. De modo que estas articulaciones que se transformaban en una esfera pública, a través de lo político, quedan en muchas ocasiones relegadas en la memoria de los grupos sociales o narrados como espectáculo por los medios de comunicación. Se diluye la esencia de lo político y "compite" con secciones de la agenda de los medios de comunicación, la cual dictará lo que es político, o si un asunto político se convierte en uno propio del espectáculo o de lo judicial, etc.

Es a través de este proceso que la lógica de lo privado invade a lo público sin que haya intervención de la política. El hecho adquiere mayor relevancia, porque la discusión se vuelve efímera y se escasean las posibilidades de buscar acuerdos en una sociedad de masas. Dicho escenario tiene varias consecuencias, entre ellas, las fracturas sociales a mediano y largo plazos, además del conflicto mismo. Ésta es una de las características fundamentales del espacio público en el contexto neoliberal.

La crisis de lo político ha conducido a la reconfiguración del espacio público, el cual se ha vuelto más heterogéneo y complejo. Es un espacio que restringe su apertura y libertad del discurso en el momento que excluye de la discusión a numerosos grupos sociales, quienes no pueden hacer visibles sus propuestas y visiones del mundo; los asuntos que se exponen no son comunes para todos sino para ciertos grupos de poder. Asimismo, estas condiciones restan autonomía al debate, porque una élite política y económica es la que lo dirige y acapara. La recomposición del espacio público ha sido también resultado de la reestructuración de los Estados-nación a partir del movimiento del capital en el mundo. Autores como Calva (1999), Alva de la Selva (2006) o Calvento (2006) han estudiado cómo el neoliberalismo tomó forma en América Latina y coinciden en los sucesos sociohistóricos que detonaron su punto de partida. En varias naciones de esta latitud, las políticas económicas neoliberales fueron puestas en 
marcha en las últimas décadas del siglo XX y tuvieron efecto en prácticamente todos los aspectos de la vida social. Aunque las experiencias de los gobiernos neoliberales en cada uno de ellos fueron diferentes, su pasaporte de arribo a esta región está estrechamente ligado a cuestiones económicas materializadas durante el Consenso de Washington en 1989: el Fondo Monetario Internacional y el Banco Mundial organizaron un encuentro en el que participaron funcionarios del Departamento de Estado de Estados Unidos, dirigentes de países industrializados, presidentes de bancos internacionales, entre otros tomadores de decisiones (Calvento, 2006, p. 48).

La globalización ha traído nuevas dificultades para establecer los límites del Estado en las sociedades contemporáneas. Tales límites pueden ser de dos tipos: territoriales o institucionales. El Estado gobierna un territorio en particular, pero la globalización hace que los gobiernos disminuyan el control sobre las actividades dentro del territorio. Por ejemplo, las empresas comerciales operan a escala internacional y pueden trasladar sus recursos de Estado a Estado de acuerdo con su voluntad. Las actividades de los mercados internacionales pueden desestabilizar gobiernos, los cuales han perdido control sobre sus propias economías (Abercrombie, Hill y Turner, 2006). Una de las características del comportamiento del capital a nivel mundial es que no tiene solidaridad con los ciudadanos ni apego a los territorios, por eso la responsabilidad que se tiene hacia los ciudadanos se subordina bajo la conveniencia de los intereses de las personas que mueven al capital. Esto se percibe en medios de comunicación como la radio. Los medios comerciales buscan rentabilidad antes que servir al público con contenidos de utilidad social. En este contexto, el Estado tiende a reducir su interés en el bienestar social, el cual, dentro de los gobiernos neoliberales, se ha entendido como "un gasto social" y no como "inversión social" y ha contribuido a proveer menos servicios públicos a los ciudadanos, lo que impacta en su calidad de vida. Esto se ha manifestado en diferentes campos, como la salud, educación, cultura,... Para México, este hecho ha representado un problema de fondo, porque, según señala Ortega, "el Estado mexicano ha renunciado a tener un papel rector en el desarrollo cultural de nuestra sociedad y ha dejado en las manos del mercado las directrices de este desarrollo" (Ortega, 2007, p. 100).

Los medios comerciales también han presionado al Estado para imponer sus reglas y normas con el fin de que éste los beneficie jurí- dicamente. Salvo excepciones, el Estado mexicano, desde los 80 , fortaleció aún más el poder de los medios comerciales con mecanismos jurídicos, políticos y el respaldo de los gobiernos en turno para fungir como los principales canales de comunicación con la sociedad. De esta forma, el modelo comercial se fue apoderando del espacio público, en donde a través de los contenidos, salvo excepciones, se han encargado de decidir qué es lo público para los ciudadanos; es decir, cuáles fenómenos son de ámbito "común" y para "todos". En vez de fungir como canales de difusión nacional que abren la comunicación para los mexicanos, la restringen a la participación de actores sociales pertenecientes a las cúpulas de poder. Son éstos para quienes fomentan su visibilidad social y les conceden mayor poder mediante estas acciones. Para el resto de la población, la expresión de su voz es limitada, generalmente a través de correos electrónicos o como actores referentes en los relatos de las noticias o programas de "debate"; sólo en ocasiones se hace visible en momentos coyunturales, en casos de acciones criminales o catástrofes. Uno de los problemas fundamentales de esta nueva faceta es que la expansión mediática privada limita la construcción de la sociedad civil. Los medios comerciales en México han demostrado en su mayoría que el debate que emprenden no es abierto ni común a todos; tampoco es autónomo y sólo le dan visibilidad a los grupos sociales que ellos deciden y cómo ellos deciden.

Los medios de comunicación son especialmente importantes en el fortalecimiento de la sociedad civil en México y América Latina, porque pueden contribuir a su organización. En la región existen condiciones históricas similares que no han permitido su fortalecimiento; por ejemplo, la pobreza extrema, la desigualdad social y poca capacidad para articularse por parte de los ciudadanos. Para su organización, se necesitan métodos, estrategias, creatividad e intuición, y capital cultural para facilitar redes sociales con otros actores políticos. Gran parte de las comunidades en esta región no cuentan en ocasiones con el capital cultural necesario, proveniente del ámbito privado (familia, escuela, trabajo). Tampoco existe una cultura de lo público, donde la ciudadanía genera una conciencia de sus derechos civiles; reproduce los deseos para una mejor calidad de vida; aprende a argumentar y a deliberar para generar acuerdos con otros actores políticos. Es decir, practicar la organización para generar el cambio social; sobre todo, aprende a tomar decisiones y a ma- 
nejar las tensiones naturales que ejercen con el Estado a través de la sociedad civil.

La expansión de las políticas neoliberales a nivel mundial también tuvo repercusiones en las decisiones políticas y económicas en México. El gobierno de Miguel de la Madrid apostó a un proyecto de nación que giró en torno a la lógica del libre mercado y que afectó a la mayoría de las instituciones estatales del país. Su visión favorecía las leyes capitalistas a través del debilitamiento del Estado, el cual fungiría como un administrador que permitiría el libre flujo del capital y limitaría su intervención en los asuntos públicos (Meyer, 2006, p. 898).

En materia de comunicación, las políticas del nuevo proyecto neoliberal contribuyeron a fortalecer los monopolios de comunicación ya existentes, así como la concentración del poder de los grupos económicos que participaban en la radio (Sánchez Ruíz, 2005, p. 424). Algunos de estos grupos eran: Organización Radio Centro, Grupo Acir, Radiodifusoras Asociadas SA (RASA), Grupo Radio Mil, Radio Programas de México (RPM). Pero la expansión no sólo fue para la radio, sino para la industria audiovisual de medios privados. Televisa contaba con una estructura monopólica, la cual se fortaleció aunque con atropellos, al no poder competir desde los Estados Unidos- hacia finales de los 80. Al respecto, Sánchez Ruíz afirma que, "en 1988, Eco comenzó trasmisiones desde México directamente a Europa, mediante la interconexión de cinco satélites internacionales. Tanto Emilio Azcárraga Vidaurreta, como Emilio Azcárraga Milmo, exhibieron siempre una vocación por la expansión internacional de sus negocios" (Sánchez, 2005, p. 425).

Era claro que esta expansión de la industria audiovisual privada iba llenando los huecos de poder que no eran cubiertos por el Estado; tenía gran influencia sobre un amplio sector de la sociedad, mientras, como analizaremos enseguida, los medios estatales quedaban marginados $y$, en ocasiones, usados por el Gobierno federal y gobiernos estatales como instrumentos de propaganda.

\section{I. REORDENAMIENTO EN LA ESTRUCTURA DE LOS MEDIOS ESTATALES Y LAS POLÍTICAS NEOLIBERALES. 1982-1988}

Miguel de la Madrid apoyó la expansión de la industria de radiodifusión privada como parte de su proyecto de gobierno: se fortaleció la concen- tración, se potencializó tecnológicamente la radiodifusión y se propagó la banda FM. Asimismo, su mandato se caracterizó por poner en marcha políticas para reducir la participación del Estado en asuntos económicos y culturales. Pero, paradójicamente, fue el presidente que amplió el espectro de la radio estatal (impulsó la creación de sistemas de radiodifusión en 12 estados); a los tres meses de llegar al poder, comenzó su restructuración bajo el proyecto conocido como Sistema de Comunicación Social. “Es curioso -afirma Sánchez Ruíz- que al gobierno de Miguel de la Madrid se le suele atribuir el haber iniciado el 'viraje neoliberal'... pero en materia de medios tendió a fortalecer y ampliar la participación gubernamental" (Sánchez Ruíz, 2005, p. 422). Alva de la Selva explica, sin embargo, que esta acción se hizo con el fin de contrarrestar los descontentos sociales y legitimar las novedosas "políticas" neoliberales. De la Madrid convocó al "Foro de Consulta sobre Comunicación Social” en 1983. El evento, según la autora:

Precedió a la elaboración del Plan Básico de Gobierno, el cual inauguraba la política de convocar a la sociedad y 'escucharla', pero no para darle entrada a la participación de ésta en la gestación de las políticas, sino como estrategia legitimadora para mantener inalterados los aspectos estructurales del sector. (Alva de la Selva, 2006, p. 163).

Ciertos grupos sociales más activos de la población, como aquellos conformados por especialistas de los medios, investigadores y académicos participaron con propuestas concretas al Ilamado del gobierno; propuestas aglutinadas en el "plan maestro" que poco se tomaron en cuenta en el Plan Nacional de Desarrollo (PND), el cual se anunciaría semanas después. Dicho plan, "establecía la creación de tres institutos autónomos y con personalidad jurídica propia para la radio, la televisión y la cinematografía, con el fin de "atender la tarea de difusión del Estado'." (Alva de la Selva, 2006, p. 163).

\section{Sánchez Ruíz añade:}

...Como parte de la Dirección de Radio (Instituto Mexicano de la Radio), el Instituto Mexicano de Cinematografía (IMCINE) y el Instituto Mexicano de Televisión (IMEVISION)[...] los recursos del Estado para cada uno de estos medios pasaron a formar parte del instituto respectivo. Así, por ejemplo, las estaciones radiofónicas comerciales que reciéntemente había adquirido el gobierno [en el sexenio de López Portillo], se adjudicaron al IMER... (Sánchez Ruíz, 2005, p. 422). 
El IMER se creó el 23 de marzo de 1983 -una red de radiodifusoras distribuidas en varias partes del país- con 21 estaciones al aire en AM, FM, onda corta y una en el canal libre internacional, 4 concesionarias (la cuarta estación fue la XEQK-AM) y el resto permisionarias, distribuidas en el DF y diversas ciudades en los estados de Coahuila, Sonora, Chihuahua, Baja California, Chiapas, Quintana Roo, Michoacán, Oaxaca y Tlaxcala. Además, la institución estableció convenios con 31 radiodifusoras estatales, universitarias e incluso comerciales para trasmitir "El Noticiario". En el mismo año, en el DF se abrieron 7 estaciones, una de ellas dedicada solamente a programación infantil y otra informativa. En la provincia la programación era variada pero predominaban los contenidos culturales; se trataba de una oferta distinta a aquélla de la radio comercial. Entre los objetivos de este organismo, publicados el 25 de marzo del mismo año en el Diario Oficial de la Federación, destacaban: contribuir a la integración nacional y descentralización cultural y establecer representaciones en México y el extranjero. Para Romo, el proyecto se convirtió en la "primera acción concreta y amplia que el Estado mexicano toma a favor de la radiodifusión estatal, ya que hasta entonces, había esfuerzos aislados..." (Romo, 1990, p. 135). Para esta investigadora es claro que la radiodifusión estatal recibió un gran impulso. "Con ello, la desproporción existente entre la radio comercial y la no lucrativa, que al principio del sexenio representaba el 3.5 de las emisoras, ha disminuido ya que "la otra radio', al final del periodo, representa el 11.37 por ciento" (Romo, 1990, p. 55). Lo más importante era que la radio estatal crecía en un contexto en el que, según Alva de la Selva, había "una densa estructura de concentración, en buena medida radicaba en las empresas y grupos familiares que habían impulsado 'la época de oro' de la radio tiempo atrás, la ya poderosa industria aprovechaba la etapa de bonanza" (Alva de la Selva, 2006, p. 164).

Es cierto que De la Madrid apoyó el surgimiento de los sistemas estatales de radio y el IMER, pero sólo se trató de un impulso a la infraestructura. La creación de estas radios parecía el resultado de un discurso político que simulaba el apoyo a la educación y la cultura pero, en el fondo, no hubo un verdadero proyecto en el que el ejecutivo enmarcara qué quería hacer con estas radios, cuál sería su destino y cómo se desarrollarían; no se supo si serían parte de un plan educativo o cultural o si estarían destinadas para lo que los gobiernos decidieran. Como afirma Alva de la Selva (2006, p. 163) se trató de una acción política que no se delineó dentro de una política de comunicación que se suponía tendría que realizarse a partir del plan de comunicación social que el mismo presidente había propuesto.

En 1987, la crisis económica se acrecentaba en México. La inflación alcanzaba el 120 por ciento; había un control político de los aumentos salariales, lo cual afectó el nivel de vida del trabajador (Meyer, 2006, p. 898). En ese año, como estrategia de la "modernización económica", De la Madrid anunció la desincorporación total de algunas instituciones públicas no prioritarias para el Estado en su quinto Informe de Gobierno; entre ellas se encontraban, la automotriz, farmacéutica, petroquímica secundaria y diversas ramas de la industria manufacturera que eran instrumentos estratégicos. En otras, como la turística y recreativa, la disminución sería significativa. El sector industrial paraestatal se quedaba con 13 ramas productivas, luego que al principio de la administración había empezado con 28 (Alva de la Selva, 2006). Aunque no tocó en su discurso el tema de los sistemas de comunicación estatal que habían ampliado su presencia en varios estados de la República, era de esperarse que éstos tampoco serían prioridad para las políticas de Estado. La noción de la información y difusión de la educación y la cultura como engranajes del servicio público estaban lejos de ser una pieza clave para el desarrollo político y social del país.

En esta etapa histórica hubo esfuerzos aislados en el fortalecimiento de los contenidos informativos y culturales. Pero, por lo que restó, más allá de la expansión en la infraestructura de la radio estatal en el país, el Estado mexicano había mostrado desinterés en apoyar el desarrollo de los medios de difusión estatales. En este periodo, también se perdió la oportunidad de sentar las bases para la creación de una política del Estado mexicano para la comunicación social, en donde el modelo de comunicación tuviera cabida para contribuir a la construcción del servicio público de radiodifusión y crear las condiciones para reglamentar el derecho a la información y garantizar su ejercicio.

\section{II. 1988-1994}

Carlos Salinas de Gortari asumió la presidencia de la República en 1988 al mando de un grupo conformado por tecnócratas. El plan neoliberal siguió su curso en este sexenio (Meyer, 2006, pp. 898-899) y el caso de los medios de 
comunicación no fue la excepción ya que el gobierno Salinas desmanteló y privatizó una parte importante de las estructuras de comunicación de propiedad federal. Al igual que su antecesor, Salinas continuó con una política de amplio apoyo al modelo de radiodifusión comercial, al cual el presidente le brindó mayor proyección internacional (Sánchez Ruíz, 2005, p. 427). De acuerdo con Alva de la Selva (2003), hubo también un respaldo incondicional del partido en el poder -el PRI- al modelo comercial. "En 1988, había 857 estaciones radiofónicas comerciales y 82 permisionadas [En 1989, el gobierno Salinas] ...refrendó en forma automática a la industria de la radio y televisión medio millar de concesiones" (Sánchez Ruíz, 2005, p. 430). Contribuyó también a que la radiodifusión comercial creciera durante el sexenio, pues para 1994 ya eran 1125 emisoras concesionadas. La radio permisionada también se amplió, pero su número siguió siendo significativamente menor en relación con la radiodifusión comercial; ésta llegó a 156 estaciones en dicho año.

Las experiencias en las estaciones estatales fueron diferentes en casi todo el país; radios de reciente creación, como las asignadas a los gobiernos del Estado de México (Toluca, XEGEM AM 1600) o Querétaro (XEQUE AM 1150), realizaron proyectos novedosos en los 90 , pero no tuvieron continuidad en el mismo sexenio o en el siguiente; otras, como en Morelos (XHVAC FM 102.9), permanecieron postradas a merced de los designios presupuestales autorizados por la Secretaría de Hacienda del gobierno federal y la voluntad de los directores en turno. El mismo sistema morelense se convirtió en instrumento político de las administraciones estatales para difundir propaganda gubernamental que favorecía a su grupo político y no a todos los sectores de la sociedad; por ejemplo, el gobernador conducía un programa todos los miércoles que se llamaba "Charla con tu gobernador".

En el gobierno de Salinas se conformaron tres sistemas de radiodifusión estatal en Tamaulipas (aunque ya operaban radiodifusoras desde 1983), Chiapas y Oaxaca. Pero, al igual que el sexenio anterior, nacieron sin el respaldo de una política de Estado que garantizara su autonomía política y financiera; asimismo, una política que diseñara un plan para encauzar la conversión tecnológica al sistema digital. Ante tal escenario, estas emisoras quedaron en manos de los gobiernos de los estados, los cuales dictaron el camino a seguir de cada medio. En este sexenio la radio estatal en las entidades de la República se fortaleció en número y en infraestructura, pero las estaciones carecieron de condiciones adecuadas para su desarrollo integral; por ejemplo, no había una definición clara de la función social que debían tener estas emisoras. Por otro lado, no contaron con el apoyo económico necesario para seguir desarrollando su infraestructura o realizar sus actividades de producción; tampoco había condiciones jurídicas para impulsarlas.

El gobierno no apoyó ni política ni económicamente el crecimiento de la radio en manos del poder ejecutivo, pero tampoco las desmanteló como sí ocurrió en 1992 con otros medios de comunicación pertenecientes también al ejecutivo; en aquel año el gobierno decidió disminuir su participación en medios y puso en venta el "paquete de medios" que incluía al sistema de TV IMEVISIÓN, la Compañía Operadora de Teatros, los Estudios América y el periódico El Nacional. En julio de 1993, IMEVISIÓN se privatizó y se convirtió en TV Azteca. Por su parte, al Canal 22 del poder ejecutivo "lo salvó de la privatización un copioso grupo de intelectuales que firmó un desplegado periodístico para tal efecto. Salinas de Gortari 'graciosamente' les concedió que el 22 se dedicara a la cultura por televisión." (Sánchez Ruíz, 2005, p. 434).

Este acontecimiento, sin embargo, nos obliga a realizar una serie de preguntas: ¿Por qué Salinas decidió no privatizar la radio estatal en un contexto neoliberal en el que se vendieron las empresas no prioritarias para el Estado?-¿Por qué sólo apoyó el desarrollo de su infraestructura pero no su estructura jurídica, administrativa y programática? No hay información precisa al respecto, sin embargo podríamos inferir que 1) no era tan costosa como la televisión y como negocio era más atractivo vender a la pantalla chica; 2) la radio, por su parte, podía ser un soporte para el ejercicio del poder político debido a la facilidad de penetración del medio en casi una totalidad de los hogares mexicanos y los costos bajos de producción; 3) IMEVISION implicaba una fuerte erogación de dinero y también había presiones por parte de la televisión privada hacia la TV estatal.

Hemos afirmado que el Estado no apoyó el fortalecimiento de la estructura de la radio estatal a nivel nacional pero tampoco la desmanteló. Este hecho hizo que los logros que hubo en algunos casos fueran esfuerzos aislados. En el IMER, por ejemplo, creado una década atrás, hubo experiencias muy variadas entre las mismas emisoras del Instituto, tal fue el caso de Radio Rin (XERIN-660 AM)-estación dirigida al auditorio infantil y creada en 1984que dejó de funcionar en 1991. Sin embargo, 
otras de sus estaciones, como Radio Educación en el DF, continuaron estableciendo vínculos con ciertos sectores de la sociedad, debido a coyunturas sociopolíticas-como el levantamiento zapatista en 1994 -y a la necesidad de la población por escuchar otro tipo de información y entretenimiento que enriqueciera su vida cotidiana-.

\section{III. 1994-2000}

En estas condiciones Salinas dejó al sector audiovisual y entregó la estafeta a Ernesto Zedillo, quien, de acuerdo con diversos autores (Sánchez Ruíz, 2005, p. 430; Alva de la Selva, 2006, p. 188; Cortés e Ibargüengoitia, 2009, p. 30 ), siguió la misma ruta que su antecesor en relación con el sector de la industria audiovisual y las telecomunicaciones; sólo que en este sexenio se empoderaron más familias como la Azcárraga y Slim. Alva de la Selva (2006) afirma que las políticas de telecomunicaciones desarrolladas durante el gobierno de Salinas de Gortari bajo un modelo neoliberal se expandieron durante el sexenio de Zedillo.

Durante este mandato, se constituyeron los sistemas de radio y televisión en Puebla (1997) y Veracruz (2000), con lo que se expandía la presencia de la radio estatal en 24 estados de la República. Si bien la infraestructura crecía, el número y poder de estas radios no eran lo suficiente para hacer contrapeso a las necesidades informativas de la población a fin de siglo. Zedillo no hacía pronunciamientos en la radio estatal tampoco; los daba en la televisión comercial principalmente, lo cual mostraba su desinterés en los sistemas estatales de radiodifusión desde el poder ejecutivo. Era una manera simbólica de restarles presencia y respaldo a estos medios ante la sociedad. En este periodo Radio Educación y el IMER fueron dos medios que apoyaron a las radios estatales para cubrir algunos de los huecos de contenidos informativos, culturales y educativos de los que carecían estas estaciones. Radio Educación lo hizo a través de la ampliación de sus trasmisiones y el IMER por medio de sus repetidoras. Periodistas e investigadores, como García Bermejo (1996), Sosa (1996), Alva de la Selva (2000) y Romo (1990), quienes estudiaron el desarrollo de la radio estatal en la segunda parte de los 90, coinciden en que la situación política y administrativa, así como la relevancia social de la programación fue muy desigual en diferentes radiodifusoras del país. Hubo radios estatales que fueron afectadas financieramente; incluso el Sistema Morelense de Radio y Televisión estuvo a punto de desaparecer, al despedir a 200 trabajadores y vender sus 4 estaciones mediante licitación pública (Sosa, 1996). Entre ellas se encontraban las emisoras de Jojutla, Yautepec y Cuautla, las cuales dejaron de funcionar en 1999; hasta la fecha sólo operan como repetidoras ${ }^{3}$. La irregularidad en el funcionamiento de gran parte de las emisoras estatales y su limitada incidencia social, reflejaban la ausencia de una política de Estado en materia de medios estatales.

Ante tal ausencia, algunos académicos y periodistas de las emisoras parecían impulsar un debate sobre la necesidad de legislar los medios estatales de modo que se convirtieran en medios de servicio público; tomaban como referencia a sistemas exitosos de radiodifusión pública de otras naciones, como modelos a seguir, para que las radios y televisoras estatales en México se fortalecieran (Fernández, 1996). Dentro de este debate, el concepto de un modelo de radiodifusión estatal con la participación de patrocinio privado era un tanto nuevo para un país en el que se había estado acostumbrado a recibir únicamente la subvención económica por parte del Estado. Para algunos especialistas de los medios, el financiamiento de la radiodifusión debía ser sólo un asunto del Estado como forma de evitar su sumisión a las reglas del mercado. La discusión fue creciendo; diferentes visiones al respecto se sumaron a la consulta pública organizada por una Comisión Especial de Comunicación Social, durante la LVI Legislatura de la Cámara de Diputados, del 8 de junio al 11 de julio de 1995. En el debate se integraron más de 2500 propuestas; el tema de la relación de los medios estatales con el poder conformó parte de la agenda.

Según Solís, el encuentro tenía dos objetivos: reordenar el modelo comunicativo en México y "presentar iniciativas de ley para actualizar la legislación en materia de comunicación social, que contemple el punto de vista de la sociedad el respecto y fortalecimiento de la libertad de expresión y de prensa que consagra la Constitución" (Solís, 2009, p. 38).

La relación de la radiodifusión estatal con el Estado parecía abrir cauce a una nueva fase de diálogo en la que se tomaría en cuenta la participación de algunos sectores de la sociedad. Era un momento anhelado desde hacía un par de décadas para los miles de participantes en esta consulta y quienes representaban a distintos grupos; se trataba de voces quienes 
creían que la democratización de los medios de comunicación era fundamental para lograr el desarrollo político y social del país.

Sin embargo, los trabajos trascurrieron hasta 1998 sin poder aprobar alguna de las propuestas; el gobierno de Zedillo no les dio la importancia necesaria para impulsarlas y convertirlas en ley; los grupos radiofónicos que habían aumentado sus concesiones y los medios de comunicación de las familias Salinas y Azcárraga no querían que los sistemas de radiodifusión estatal se fortalecieran porque significaban competencia.

Es un hecho que, a finales del siglo XX, había un consenso entre actores políticos importantes en la vida nacional (algunos diputados, académicos especialistas en medios, periodistas, trabajadores de los medios, entre otros), sobre la función social que debían asumir los medios estatales: 1) tenían que ampliar sus actividades y convertirse en medios públicos; 2) eran fundamentales para el desarrollo democrático de la sociedad en México y por lo tanto tenían que fortalecerse; 3 ) su situación jurídica se tenía que actualizar y definir con mayor profundidad.

A pesar del avance en los trabajos de la sociedad organizada sobre la actualización del marco jurídico de los medios de comunicación, las iniciativas de ley no trascendieron. Con este episodio, en el gobierno de Zedillo, se impidió la posibilidad de reordenar el modelo comunicativo en México y, particularmente, poner en marcha una política de Estado que fortaleciera el funcionamiento de los medios estatales en el país de acuerdo con la realidad que vivía la sociedad en México a finales de los 90.

En suma, en el gobierno Zedillo la responsabilidad de los medios quedó bajo la tutela "de la lógica del mercado informativo 'autorregulado'." (Esteinou, 2005). El eje de dicha lógica fue el modelo de radiodifusión privada el cual, si bien ya formaba parte del mercado informativo desde décadas atrás, su estructura fue revigorizada con el proyecto neoliberal. El modelo estatal desempeñó un papel complementario en la agenda pública del Estado a pesar de la creación de nuevos sistemas de radiodifusión estatal.

\section{IV. 2001-2006}

Cuando Vicente Fox llegó a la presidencia en el 2001, amplios sectores de la sociedad abrieron sus expectativas al haber quitado al PRI del poder federal; algunas instituciones como el Ins- tituto Federal Electoral habían trabajado para que hubiera elecciones limpias y se respetara el voto. Sin embargo, existían ciertas condiciones económicas y políticas-como la inequidad o el debilitamiento de las instituciones-que limitaban la transición democrática. Los problemas para impulsar la democracia se veían acentuados con la falta de una modernización del sistema comunicativo en México; a la transición política no le había correspondido un cambio en la estructura de medios de comunicación.

Por ello se esperaba que el gobierno de Fox creara una política de comunicación donde hubiera mayor inclusión de los ciudadanos en los medios de comunicación privados y estatales. La política tendría impacto en la democratización del espacio público al permitir un mayor flujo de información y otorgar autonomía a los sistemas de radiodifusión estatal, con la puesta en marcha de un modelo de radiodifusión más equitativo que coadyuvara a la transformación del sistema político mexicano.

Con esa esperanza social, Fox llegó a Los Pinos. Sin embargo, esa confianza se fue diluyendo en tanto las acciones del nuevo presidente se alejaban de sus promesas por democratizar el Estado mexicano. La anhelada democratización se dio más en lo político, pero no se consolidó en lo social ni en lo cultural, como fue en el caso de la pluralización de los medios de comunicación. Contrario a sus promesas, a medida que transcurrían los primeros meses del primer año de su sexenio, Fox fue fortaleciendo las políticas neoliberales desarrolladas en los sexenios anteriores. En el sector mediático estas políticas beneficiaron a las principales corporaciones audiovisuales privadas, las cuales siguieron expandiendo su capital económico, político y social.

Televisa y Televisión Azteca principalmente fueron adquiriendo poderes superiores a los establecidos por la ley; su influencia era cada vez mayor en sectores empresariales, como el mercado bursátil internacional; obtuvieron más peso en las instituciones políticas como los partidos políticos; su presencia cultural en grupos mayoritarios y minoritarios de la sociedad fue obteniendo cada vez más presencia a través de sus contenidos.

El Estado renunció a sentar las directrices sobre el desarrollo cultural del país, y cedió las principales actividades de difusión informativa de la cultura y la educación a los grandes medios audiovisuales privados, los cuales se convirtieron en los canales principales de comunicación del Gobierno federal. Esto intensificó la 
desregulación en la información; la dinámica del mercado se encargaría de autorregularla (Esteinou y Alva de la Selva, 2011, p. 111). Estas empresas se convirtieron en poderes fácticos; su relación con el Estado y la sociedad se redefinió en este siglo al obtener mayor poder.

En tanto más poder se concedía a los medios privados, la radiodifusión estatal iba restando su presencia política en la arena pública. El Canal 22 no era una TV de servicio público ni representaba la realidad de la pluralidad social y cultural. Ante tal hecho, grupos sociales, entre ellos algunos intelectuales, periodistas, académicos y miembros de ONG's, así como ciudadanos interesados en contar con mejores medios audiovisuales, habían perdido la esperanza de que esta televisión ofreciera contenidos diversos y plurales, y con entretenimiento lúdico. Al cambio de siglo, el canal no representaba una opción diferente de programación; por el contrario, constituía una oferta similar a la de Televisa. El hecho, también significaba para los ciudadanos del país perder la oportunidad de contar a futuro con una red de medios públicos a nivel nacional.

Sólo hubo excepciones de medios no comerciales que lograron crear esferas de comunicación que ayudaron a dar visibilidad y reconocimiento a grupos de la sociedad civil en el espacio público local y nacional. Ante estas condiciones políticas, podemos distinguir tres eventos que dictaron la política de Fox en torno a los medios de comunicación, los cuales reforzaron el poder a los medios privados y desfavorecieron a los medios estatales: 1) el establecimiento de la "Mesa de Diálogo para la Reforma Integral de la Legislación de los Medios Electrónicos"; 2) el decretazo; 3) la Ley Televisa.

1) Establecimiento de la "Mesa de Diálogo para la Reforma Integral de la Legislación de los Medios Electrónicos".- En el año 2000-2001 se había creado un contexto político en el que parecía que las condiciones cambiarían para los 24 sistemas de medios estatales de los estados. La secretaría de Gobernación convocó a distintos sectores sociales para instalar la "Mesa de Diálogo para la Reforma Integral de la Legislación de los Medios Electrónicos" el 5 de marzo de 2001.

El tema de los medios de titularidad estatal tuvo presencia en una de las mesas; se discutió la posibilidad de que pudieran tener la definición jurídica como medios públicos. Era interesante el hecho que cada vez más sectores de la sociedad reconocieran que los medios estatales tuvieran que tener un marco jurídico como medios públicos. Para febrero de 2002, los miembros de la 'Mesa de Diálogo' deciden conformar un grupo de redacción para trasladar las propuestas a una iniciativa de ley. Sin embargo, la iniciativa de ley no transcendió más allá de un documento elaborado por representantes de la sociedad y de un debate-al que se sumaron más representantes de grupos organizados interesados en los medios- que intensificó, entre otras cuestiones, la demanda de transformar la relación de poder de los medios estatales con el Estado para que éstos pudieran ser más autónomos con respecto al gobierno y fortalecer su función social como medios estatales.

2) El decretazo.- La evidencia más clara de lo anterior se dio el 10 de octubre del 2002 con el llamado decretazo: el poder ejecutivo decretó un acuerdo presidencial sobre el manejo del 12.5 por ciento de los tiempos de Estado y modificaciones al reglamento para la Ley Federal de Radio y Televisión4. Pero en realidad el Gobierno federal ignoraba con dicho decreto el trabajo que se había realizado con la iniciativa de reforma integral de los medios electrónicos. Al Ejecutivo no le importó pasar por alto los acuerdos obtenidos con grupos de la sociedad civil en las mesas de diálogo, y al vapor puso en marcha tal reglamento en el que, entre otras cuestiones, soslayaba la transición de los medios estatales en públicos, como Fox había prometido durante su campaña presidencial. El partido en el poder había cambiado, pero no el sistema político y como consecuencia su relación con los medios estatales. Un sistema político que, a través de acciones como el decretazo, daba prioridad a los designios de las leyes del mercado y no a las demandas de los actores políticos organizados (Meyer, 2006). Con el fracaso de esta iniciativa, el gobierno de Fox coadyuvó a que el modelo comercial de medios de comunicación obtuviera más poder e injerencia en la vida pública del país; asimismo, quedaba evidente que a Fox no le interesaba el desarrollo de los medios estatales de comunicación.

Tanto las mesas de diálogo como el decretazo fueron dos eventos que motivaron a intensificar en estos años el debate sobre la importancia de fortalecer los medios estatales. Se hizo reflexionar a algunos sectores de la población sobre la importancia de los medios estatales al ser un bien público; el cual, como dice Alva de la Selva (2002) es un bien que tiene que ser defendido activamente por la sociedad organizada:

Para la sociedad está quedando claro que el cambio democrático y la democracia como forma de vida, requieren trasformaciones de muchos espacios de la vida comunitaria que por lo tanto 
no podrá darse de manera auténtica sin modificaciones profundas en la forma de funcionamiento de la radio y la televisión en este país (Alva de la Selva, 2002, p. 101).

Dichas posturas planteadas por académicos, medios estatales y culturales, y otros representantes de la sociedad civil trascendieron en el documento "Iniciativa ciudadana de reforma a la Ley Federal de Radio y Televisión" y presentado el 4 de diciembre de 2002 (Solís, 2009, p. 46), y en lo que dos años después se convertiría en un predictamen de Ley Federal de Radio y Televisión, el 24 de noviembre de $2004^{5}$. El predictamen de ley otorgaba las bases jurídicas para integrar a la radiodifusión estatal a una política de Estado y contemplaba al servicio público de radiodifusión como un derecho, el cual se debía brindar a través de los medios de Estado (Solís, 2009).

3) Ley Televisa.- Sin embargo, los esfuerzos conjuntos de miembros de la sociedad civil y de algunos legisladores no fueron suficientes para que se aprobara el dictamen. El 1 de diciembre de 2005, sorpresivamente, 327 diputados votaron a favor de una minuta para reformar las leyes de Telecomunicación, Radio y Televisión. De acuerdo con Esteinou y Alva de la Selva, se trató de:

Un proyecto de reforma a LFRTV y a la LFT, denominado popularmente 'Ley Televisa'. Fue presentado y dictaminado en ocho días, aprobado por unanimidad en siete minutos, sin mociones a favor o en contra, sin abstenciones y sin destacar la trascendencia de la misma. (Esteinou y Alva de la Selva, 2009, p. 13).

En efecto, existe un acuerdo generalizado entre académicos y especialistas de los medios en México en que no se pudo concretar esta reforma integral por la falta de voluntad política de los poderes Ejecutivo y Legislativo, así como de los intereses de la élite política y los concesionarios de los medios agrupados en la CIRT.

Uno de los hechos más significativos del debate sobre la transformación jurídica de la radiodifusión en México fue que los medios estatales y culturales del país: a) lograron fijar una postura conjunta sobre sus condiciones jurídicas; b) contribuyeron a organizar una discusión pública a través de la Red de Radiodifusoras y Televisoras Educativas y Culturales de México; c) expresaron su capacidad para ser autónomos con respecto del gobierno y decidir sus aspiraciones como medios de servicio público; d) demandaron que los medios públicos son necesarios para el desarrollo democrático del país; e) protestaron por haber sido excluidos en el proyecto de ley, entre otras cuestiones. Es evidente que la intensificación del debate entre los sectores más críticos de la sociedad obtuvo ganancias políticosociales; se logró que los partidos políticos y otras instituciones sociales añadieran en su agenda política el tema los medios públicos. Para Esteinou, en particular, uno de estos beneficios fue la conformación de una "masa de pensamiento crítico que discute abiertamente en casi todas las arenas la transformación del papel de los medios de información colectivos" (Esteinou, 2007).

\section{LOS SISTEMAS DE RADIODIFUSIÓN ESTATAL ANTE EL NUEVO SIGLO}

Lo que ocurrió en México desde la segunda mitad del siglo XX fue la creación de un sistema de radiodifusión estatal y federal con poca planeación y visión por parte del Estado. Desde el gobierno de Echeverría hasta el de Fox, se fue construyendo paulatinamente una infraestructura amorfa de radiodifusoras en casi todos los estados hasta completar 27 sistemas estatales en el 2006; muchas veces fue por decisión de los gobernadores en turno e incluso presidentes municipales. En escasas ocasiones las emisoras pudieron tener impacto en algunos sectores de la sociedad. En este periodo, el Estado sólo se planteó en momentos coyunturales que los sistemas estatales de medios debían brindar principalmente un servicio público de información y entretenimiento, y que era tan importante para el desarrollo de la sociedad como aquel de salud o educación.

En el periodo de Fox la estructura de radiodifusión estatal permaneció casi igual que en sexenios anteriores; se constituyeron 3 sistemas de radiodifusión estatal en Coahuila, Colima y Sinaloa, con lo cual la estructura de radio estatal en el país logró presencia en 27 entidades. Además, algunos sistemas iniciaron a trasmitir en FM, como en el caso de Aguascalientes (el 17 de noviembre de 20056 ) o el mismo sistema de Puebla, el cual abrió en ese mismo sexenio 4 emisoras más ${ }^{7}$. La creación de estos sistemas de radiodifusión y de emisoras en otras entidades de la República no alteraron la relación de poder con los gobiernos estatales, cuyo poder ejecutivo continúo difundiendo mensajes sobre sus éxitos políticos o fortaleciendo la propaganda en momentos electorales, con el fin de mantenerse en el poder. Tal es el caso de la emisora del Instituto Colimense de la Radio y Televisión, la cual desde el inicio de sus trasmisiones es- 
tuvo apegada a la línea gubernamental. En 2003, la radio dejó de ser parte del IMER y se convirtió en organismo descentralizado. En 2004 pasó a manos del Instituto colimense; en 2005 la emisora Conexión XEBCO (1210 AM) cambió de programación, aunque en sus contenidos se cuidaba la imagen del gobernador Jesús Silverio Cavazos y se difundía de manera promocional las actividades del gobierno estatal ${ }^{8}$.

El nivel de autonomía política fue similar en Aguascalientes; el desarrollo del sistema estatal estuvo ligado con los designios del gobernador en turno, Luis Armando Reynoso. Hacia el final del gobierno de Fox, la 13020 AM inició sus trasmisiones en el 92.7 FM. Aunque las dos radios no lograron ser autónomas con respecto del gobierno estatal, el sistema de Radio y Televisión de Aguascalientes (RyTA) pudo fortalecer su programación. Las estaciones de radio representaron una alternativa a las emisoras culturales y comerciales, con programas de diferentes enfoques principalmente musicales (rock, clásica y de otros géneros) y noticiosos. Para el investigador Salvador de León (comunicación personal, 25 de julio de 2014), "no se puede negar que estos medios, más que públicos han sido gubernamentales, y su proyecto se ha construido desde el gobierno del Estado, así como su uso propagandístico."

En los primeros seis años del siglo, se crearon radiodifusoras estatales en casi toda la República; sólo los estados de San Luis Potosí, Yucatán, Baja California, Chihuahua y Durango faltaban por tener un sistema de radiodifusión estatal. El desarrollo de esta infraestructura se logró sin la existencia de una política de Estado; en muchos casos, el destino de las radios se debió al impulso de los gobiernos estatales, de los directivos y trabajadores de las emisoras.

La existencia de estrategias y no de una política de Estado en materia de medios estatales impactó particularmente en diversos grupos sociales marginados, quienes desde hacía varias décadas no habían tenido espacio de expresión en los medios estatales ni en otras instancias de la vida pública; estos sectores tenían demandas sociales específicas, pero no un lugar dónde canalizarlas ni hacerlas visibles ante la sociedad, salvo las protestas públicas. Solís (2002, pp. 313-316) dice que en el 2000, ya operaban 1449 estaciones en el país tanto en la banda AM (851) como en la FM (598); 1141 eran emisoras concesionadas contra 308 permisionadas, de las cuales 184 pertenecían al gobierno de los estados y 124 a asociaciones civiles, personas físicas, instituciones educativas, municipios, IMER e Instituto Nacional Indigenista. Las radios concesionadas constituían un 79 por ciento, mientras que las permisionadas un 21; de éste 21, las radios de los gobiernos estatales conformaban el 13 por ciento.

La creciente desproporción entre los dos modelos de radiodifusión se debió al apoyo del Gobierno federal hacia el sector de los medios audiovisuales privados (Ortega, 2005, p. 106). La disparidad en el desarrollo entre el modelo de radio comercial y estatal fue el resultado de las políticas emprendidas desde los 80 y principios de los 90. (Esteinou, 2001, pp. 160-162). Es cierto que el presupuesto neto de muchas emisoras fue en aumento, pero, en términos relativos, dicho financiamiento no cubría las necesidades crecientes de las emisoras estatales del país para realizar producciones que requerían más elementos, como los documentales o la cobertura informativa, por citar algunos ejemplos.

\section{REFLEXIONES FINALES}

Hasta aquí, hemos ofrecido un panorama general sobre el desarrollo de la radiodifusión estatal en México desde su surgimiento; y hemos discutido sus condiciones políticas y su relación con la sociedad. Después de haber trazado este recorrido histórico, queda claro que los medios de servicio público pudieron haberse desarrollado en los sistemas estatales, pero el hecho de que al Estado no le interesó impulsar una política ni creó una ley que le dieran sustento jurídico a este tipo de medios, fueron razones que impidieron vincular las primeras emisoras estatales con la noción de servicio público. En su lugar, el surgimiento de estas emisoras se dio de manera aislada y, en algunos casos, incluso funcionaron como medios propagandísticos del gobierno. Esta tendencia continuó durante los gobiernos neoliberales hasta el sexenio de Fox. Los medios estatales fueron relegados por el Ejecutivo (federal y estatal) a un segundo plano; en su lugar se le dio prioridad a la expansión de la radiodifusión privada. A pesar de que hubo algunas excepciones de sistemas de radio estatal que lograron incidir en ciertos sectores de la población y que hubo un crecimiento en cuanto a la infraestructura, se desaprovechó su potencial para contribuir a ampliar la discusión en el espacio público y visibilizar a grupos sociales minoritarios y mayoritarios. 
La revisión histórica anterior es de suma importancia para entender la necesidad de definir políticas culturales que vinculen los sistemas de servicio público a un proyecto de nación; trasmitir contenidos de utilidad social para una sociedad cada vez más diversa y plural; incluir más voces que representen a los grupos sociales a través de productores independientes; lograr el acceso universal cuando las sociedades tienden a ser más desiguales; producir contenidos plurales para naciones multiculturales; mantener un periodismo independiente; redefinir el papel de los consejos audiovisuales que representan diversos grupos de la sociedad; brindar a los ciudadanos, mediante este servicio, el derecho a la información; contribuir a fortalecer la identidad nacional, construcción ciudadana y a potencializar el debate en el espacio público.

El servicio público se remite al interés general y es una obligación del Estado. La gestión de un servicio público puede entregarse a empresas públicas o a empresas privadas; las instituciones de servicio público deben cumplir las exigencias de continuidad de servicio, accesibilidad o igualdad y adaptabilidad. La actividad de interés general no puede abandonarse en la iniciativa privada y al puro juego de las leyes de mercado, y por tanto el Estado asume directamente su responsabilidad y su control, sometiéndola, si fuera necesario, a un órgano jurídico especial.

Como se ha analizado, la expansión del neoliberalismo ha impuesto nuevas condiciones en el desarrollo del servicio público en las primeras décadas de este siglo. No obstante las presiones de la supremacía de los valores del mercado y el desinterés del Estado en México hasta principios del siglo XXI hubo ciertos sectores de la sociedad que exigían configurar un modelo de radiodifusión estatal con principios y características de servicio público. Asimismo, pugnaban por una programación distinta a la que se difundía en los medios comerciales.

\section{NOTAS}

1 Hasta el 1 de diciembre de 1987, ya como parte del Sistema de Radio y Televisión de Aguascalientes, se convierte en organismo descentralizado.

2 En esta investigación se entenderá al neoliberalismo como aquella extensión contemporánea del capitalismo, caracterizado por la reducción del poder del Estado y con ello el de sus instituciones. Es una fase del modo de producción capitalista que intenta implantar una sola forma de ideología y de ver el mundo, desde la base de una economía de mercado global. En otras palabras, se impone como visión totalizadora de gobernar, desde el ámbito de lo doméstico y cotidiano hasta modelos macroeconómicos y políticos.

3 Información proporcionada por la Dirección de Radio y Televisión del Congreso del Estado de Morelos.

4 Para un seguimiento de los hechos, leer la revista Proceso, del 5 de diciembre (2004) y el periódico La Jornada, en sus ediciones del 1, 10, 16 de diciembre (2004), 16 de febrero y 2 de junio (2005).

${ }^{5}$ En noviembre, el predictamen pasó de las comisiones al pleno de la cámara de Senadores y se empezó a discutir el primero de diciembre de 2004. El 15 de diciembre se clausuró el periodo de sesiones y no se aprobó el predictamen de ley. Posteriormente hubo otras oportunidades fallidas en el siguiente año (15 de febrero de 2005; 2 de junio de 2005; 1 de septiembre durante el periodo de sesiones de la 26 legislatura de la cámara de Senadores).

6 http://www.aguascalientes.gob.mx/ryta/, consultado el 4 de diciembre de 2018.

7 Huauchinango (XHNGO 98.9 FM), el 9 de enero de 2004; Libres XHLIB 95.9 FM, el 8 de junio de 2004; Teziutlán XHTEZ 90.9 FM, el 9 de enero de 2005; Tehuacán (SHEHU 93.1 FM), el 19 de enero de 2005.

${ }^{8}$ Los directores que le siguieron a Leticia Galván tuvieron ese mismo perfil, incluso hubo un director que venía de la radio grupera, Alberto Ramos. Entrevista con Marina Vázquez Guerrero, 28 de julio de 2014.

\section{REFERENCIAS BIBLIOGRÁFICAS}

- Abercrombie, N., Hill, S. y Turner, B. (2006). Dictionary of Sociology. London: Penguin Books.

- Alva de la Selva, A. (1982). Radio e Ideología. México: El Caballito.

- Alva de la Selva, A. (1988). Radio: punta de lanza del consorcio. En Trejo. R (coord.), Las redes de Televisa. México: Claves Latinoamericanas.

- Alva de la Selva, A. (2000). Del corazón del cuadrante nacional: la radio comercial de la ciudad de México. En Rebeil, M. (comp.), Perfiles del cuadrante, experiencias de la radio. México: Trillas.

- Alva de la Selva, A. (2002). Perspectivas de los medios públicos en la sociedad globalizada, Sociedad y medios electrónicos en México. Propuestas sociales. En Solís, B. (coord.), Los medios electrónicos en el marco de la Reforma del Estado en México. México: Fundación Konrad Adenauer, AC.

- Alva de la Selva, A. (2003). Quince años de televisión en México. De la expansión a la cúpula del poder, Revista Mexicana de Comunicación, 83, 23-24.

- Alva de la Selva, A. (2006). Políticas de telecomunicaciones y sociedad de la información 
en México (Tesis doctoral). Universidad Nacional Autónoma de México, México.

- Calva, J. (1999). El modelo neoliberal mexicano. México: Juan Pablos.

- Calvento, M. (2006). Fundamentos teóricos del neoliberalismo: su vinculación con las temáticas sociales y sus efectos en América Latina, Revista Convergencia, 41, mayo-agosto de 2006.

Recuperado de:

https://convergencia.uaemex.mx/article/view/14 10/1078.

- Cortés, G. e Ibargüengoitia, A. (2009). La radio en México (1990-2008) (Tesis de grado). Universidad Nacional Autónoma de México, México.

- Esteinou, J. (2001). La democratización de los medios de comunicación en México. En Cerdán, J. y Aceves, F. (eds.), Anuario de investigación de la comunicación. Nuevo León: CONEICC.

- Esteinou, J. (2005). Hacia un nuevo modelo de comunicación de servicio público en México, Ámbitos, 13-14. Recuperado de: http://www.razonypalabra.org.mx/anteriores/n4 6/jesteinou.html.

- Esteinou, J. (2007). Espacio público, medios de información y transición presidencial en el 2006, Razón y palabra, 55. Recuperado de: http://www.razonypalabra.org.mx/anteriores/n5 5/jesteinou.pdf.

- Esteinou, J. y Alva de la Selva, A. (2009). La "Ley Televisa" y la lucha por el poder en México. México: Fundación Friedrich Ebert.

- Esteinou, J y Alva de la Selva, A. (2011). Los medios electrónicos de difusión y la sociedad de la información. México: SRE.

- Fernández, F. (1982). Los medios de difusión masiva en México. México: Juan Pablos.

- Fernández, F. (1991). La radio mexicana: centro y regiones. México: Juan Pablos.

- Fernández, F. (1996). La posibilidad de la radio pública en México, Revista Nexos, 222. Recuperado de: https://nexos.com.mx/?p=7879.

- Fernández, F (2000). Impacto de la concentración de los medios. En Solís, B. (coord.), Los medios públicos de comunicación en el marco de la reforma del Estado en México. México: Cámara de Diputados.

- García, C. (1 de agosto de 1996). Las radios culturales en la marginación. El Financiero, p. 54.

- Martell, L. (2017). El servicio público de radio en México en tiempos del neoliberalismo. México: UNAM.

- Mejía, F. (1989). La industria de la radio y la televisión y la política del Estado mexicano. México: Fundación Manuel Buendía.
- Mejía, F. (2007). Historia mínima de la radio mexicana, Revista Comunicación y cultura, 1 (1), 1 26.

- Meyer, L. (2006). De la estabilidad al cambio. En Historia General de México. México: El Colegio de México.

- Ortega, F. (2004). Espacio público y legitimidad política. En Reflexiones sociológicas. Madrid: CIS.

- Ortega, P. (2005). Medios de estado, una transición incompleta. En Solís, B. (coord.), Retos y perspectivas de la comunicación en el marco de la Reforma del Estado. México: Fundación Konrad Adenauer, AC.

- Ortega, P. (2006). La otra televisión: Por qué no tenemos televisión pública. México: UAMXochimilco.

- Ortega, P. (2007). Muchos canales no es sinónimo de pluralidad. Dos empresas una voz. Anuario de investigación 2006. México: UAM-X.

- Quiroz, S. (2000), La Comisión Nacional de Televisión de Colombia, en Solís, B. Los medios públicos de comunicación en el Marco de la Reforma del Estado en México, México: Cámara de Diputados.

- Romo, C. (1990). La otra radio, Voces débiles, voces de la esperanza. México: Fundación Manuel Buendía-IMER.

- Sánchez Ruíz, E. (2005). Los medios de comunicación masiva en México, 1968-2000, en Bizberg, I. y Meyer, L. (coord.), Una historia contemporánea de México: actores. México: Océano.

- Serrano, A. (2006). Marcos constitucionales y el servicio público de radiotelevisión en América Latina. Un tema relevante para la UNESCO. Costa Rica: UNESCO.

- Solís, B. (coord.) (2002). Los medios electrónicos en el marco de la Reforma del Estado en México. México: Fundación Konrad Adenauer, AC.

- Solís, B. (2009). De cómo llegamos hasta aquí... Los antecedentes de la 'LeyTelevisa'”, en Esteinou, J. y Alva de la Selva, A. (coords.). La "Ley Televisa" y la lucha por el poder en México. México: Fundación Friedrich Ebert.

- Sosa, G. (1996). Focos de emergencia para la radio mexicana, Revista Mexicana de Comunicación, 43, 11-14.

- Toussaint, F. (coord.) (1985). Televisa: una semana de programación. Mente sana cuerpo sano, en Trejo, R(coord.). Televisa el quinto poder. México: Claves Latinoamericanas.

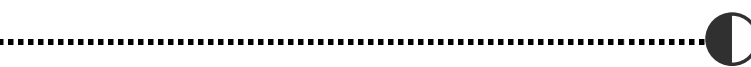

